\title{
Effect of SIM on Knowledge Regarding Computer Vision Syndrome and its Prevention Among Computer Professionals: A Quasi Experimental Approach
}

\author{
Shiny T Sam ${ }^{1}$, Rinu J George ${ }^{2}$ \\ ${ }^{1}$ Lecturer, MGM Muthoot College of Nursing, Pathanamthitta \\ ${ }^{2}$ Lecturer, Jimma University, Ethiopia
}

\begin{abstract}
Computers are now a way of life, something that you cannot do without. As the number of people working on computers continues to grow each year, the number of people encountering temporary vision problems due to computer use also increases. Computers do not harm your eyes, but often cause temporary problems. Aims of the study: To evaluate the effectiveness of (SIM) selfinstructional module on knowledge regarding computer vision syndrome and its prevention among computer professionals in selected area of Bhilai. Materials and methods: A one group pretest and posttest design was used to accomplish the objectives of the study. In this study non-probability convenient purposive sampling was done to select 60 subjects in the study. After the pretest next (SIM) was administered and after 7 days posttest was conducted. Major findings: There was a significant increase in the knowledge level of participants after providing the SIM. Conclusion: (SIM) was found to be powerful in increasing the knowledge level of the participants regarding computer vision syndrome and its prevention.
\end{abstract}

Keywords: Computer Vision Syndrome, Self Instructional Module, Prevention, Computer Professionals

\section{Introduction}

Human eyes were meant for hunting and farming and even if we have moved far ahead with technology, our bodies still have to catch up on the metamorphosis from far work to fixed close work. When you look in the distance, your eyes are relatively relaxed and at rest. But while doing near work, such as reading your computer screen, muscles in your eyes have to work harder to keep a clean near focus. These muscles get tired after extended use, resulting in eyestrain, neck pain, blurry near vision, headaches or difficulty changing focus. Dry eyes can also occur because we tend to blink less as we concentrate on our computer screen and keep our eyes wide open when working at the computer, resulting in drying up of the tear film.

Most studies indicate that computer operators, who view their video display terminals (VDTs), report more eye-related problems than non- video display terminals office workers. A number of investigators have indicated that visual symptoms occur in $75-90 \%$ of video display terminals workers [1].

In contrast to the popular conception regarding carpal tunnel syndrome, a study released by National Institute for Occupational Safety and Health (NIOSH) showed that only $22 \%$ of video display terminals workers have musculoskeletal disorders [2].

The American Optometric Association defines computer vision syndrome (CVS) as that complex of eye and vision problems related to near work which are experience during or related to computer use'. The symptoms can vary but mostly include eyestrain, headaches, blurred vision (distance and/or near), dry and irritated eyes, slow refocusing, neck and/or backache, light sensitivity, and double vision [3].

A cross sectional survey on 152 computer workers to study pathology associated with use of video display units (VDU), observed that $23.6 \%$ benefited from Visual examination and concluded that ergonomic evaluation of work environment is necessary to prevent symptoms of computer vision syndrome [4].

A study among 100 subjects while performing an editing task on computer screen positioned at different angles, observed that preferred angle to tilt of the screen was such that it was parallel with the frontal plane of the face [5].

An experimental study on 56 subjects on reading performance and visual comfort on high resolution and video graphic array (VGA) monitor found that high resolution monitors resulted in $17 \%$ faster reading rate and only $38 \%$ symptoms [6].

In a study on work related cumulative trauma disorders and the relationship with gender, found that women are more likely to develop work related cumulative trauma disorders than men due to psychological strain at work, household work, body size, strength [7].

\section{Need for the Study}

In the past decade, computer use among children in the United States has become pervasive. Consider these statistics:

- 94 percent of American families with children have a 


\section{International Journal of Science and Research (IJSR) \\ ISSN (Online): 2319-7064}

Index Copernicus Value (2013): 6.14 | Impact Factor (2014): 5.611

computer in the home with access to the Internet.

- The amount of time children ages 8 to 18 devote to entertainment media (including computer and video games) each day has increased from 6.19 hours in 1999 to 7.38 hours in 2009.

- In 2009, 29 percent of American children ages 8 to 18 had their own laptop computer, and kids in grades 7 through 12 reported spending an average of more than 90 minutes a day sending or receiving texts on their cell phones.

A large study conducted by the National Eye Institute and published in the December 2009 issue of Archives of Ophthalmology found that the prevalence of nearsightedness among Americans has increased from 25 percent to 41.6 percent of the population over the past 30 years - an increase of more than 66 percent[8].

Also, among people with 12 or more years of formal education, the prevalence of myopia is now as high as 59.8 percent.

The University of Alabama at Birmingham UAB study also suggests computer vision benefit programs can add significant economic benefits to companies with large numbers of computer-using employees. Study results show that:

- Providing computer vision care to all employees who use computers, even those who are not experiencing computer vision syndrome symptoms, results in significant productivity gains and cost savings for employers.

- Musculoskeletal problems, which may be caused by computer-related vision problems, can potentially be minimized or eliminated by including computer vision care in a comprehensive vision care benefits program.

- Employees performing tasks with particularly demanding visual requirements, such as accounting, document editing, CAD (computer-assisted design) work, electronic design and engineering, could benefit even more from computer eyewear than the average computer worker.

- A computer vision benefits program likely will also lower incidence of workers' compensation claims among computer workers.

According to National Association of Software Companies (NASSCOM, 1999), India, the Information Technology demand in India is 4,00,000 per year. Around 1 million computer professionals are graduating from various courses per year. At present there are 15 million registered users and another unaccountable millions of regular daily users (CTD News, 1996) [9].

In spite of such a population involved in computer related jobs, no significant research in computer related health problems has been carried out in India as compared to Western countries. It is high time for nurses, who are accountable for educating their clients for maintenance of healthy lifestyle to start creating an awareness among people who are at risk for developing computer vision syndrome, the preventive strategies to be adopted. The investigator feels that is the responsibility, of nurses as health care professionals to start spread heading awareness programmes of computer vision syndrome among computer professionals and also believes that the present study will be a stepping stone in this direction.

\section{Review of Literature}

A cross-sectional study among 498 males and 785 females professional computer users to describe prevalence of work related health problems among professional computer users reported that women have a higher proportion of symptoms [10].

Computer users at risk: Health disorders associated with prolonged computer use this research aims to assess the prolonged use of computers and their effects on human health. $25.9 \%$ are facing all health disorders. The other respondents who are of age more than 30 years, majority (74.1\%) reported all problems, $73.3 \%$ have shown stress, $43.8 \%$ have shown carpal tunnel syndrome and musculoskeletal disorders and only $25 \%$ have computer vision syndrome[11].

Knowledge, attitudes and practices in Indian Ophthalmologists. The chief presenting symptoms were eyestrain $(97.8 \%)$, headache $(82.1 \%)$, tiredness and burning sensation $(79.1 \%)$, watering $(66.4 \%)$ and redness $(61.2 \%)$. Ophthalmologists using computers reported that focusing from distance to near and vice versa $\left(\mathrm{P}=0.006, \chi^{2}\right.$ test $)$, blurred vision at a distance $\left(\mathrm{P}=0.016, \chi^{2}\right.$ test $)$ and blepharo $\operatorname{spasm}\left(\mathrm{P}=0.026, \chi^{2}\right.$ test $)$ formed part of the syndrome [12].

\section{Materials and Methods}

This study was conducted in the Shri Shankaracharya College of Nursing, Amdi Nagar, Hudco , Bhilai, India, during February to March 2012. Data collection was done after taking formal written permission from the Principal of Shri Shankaracharya College of Nursing and the Centre Manager of Computer Centre. Non - probability purposive convenient sampling of 60 subjects was done and self structured questionnaire was adopted to approach the subject consent of the sample was taken. The study protocols and methods were approved by institutional ethical committee.

In this study, a self-structured questionnaire, one group pretest and posttest research design, questionnaire in English and Hindi languages were given to participants after obtaining a written informed consent. Informed consent was obtained from each participant ensuring the confidentiality of the data.

\section{Description of Tool}

The structure interview was used to collect the relevant data, because interview allows the respondent to clarify answers were recorded immediately and to ensure objectivity. Selfstructured questionnaire and standardized tool was selected because it is an efficient method of recording and data gathered is objective.

The interview schedule consisted of 2 sections consisted of:Section A: - Socio demographic data. 


\section{International Journal of Science and Research (IJSR) \\ ISSN (Online): 2319-7064}

Index Copernicus Value (2013): 6.14 | Impact Factor (2014): 5.611

Section B: - Self structured questionnaire

\section{SECTION-A: - Socio demographic variable}

This section consist of 10 items pertinent to the demographic data of the computer professionals regarding the gender, age, education, area of residence, How many hours you use computer in a day?, Do you have any vision problem after using computer?, Professional education, Monthly Income, Occupation, Experience in computer field.

\section{SECTION B: -}

Comprises of 32 question related to computer vision syndrome. The split half method was used to test the reliability of the tool the test was first divided in to two equivalent half and co-relation was found by using KarlPearson correlation of co-efficient formula. The reliability of the tool was found to be 0.83 . So, tool was found to be highly reliable for data collection. Data was analysed in term of objective $\&$ by using both descriptive inferential statistic in the following manner. Organizing data in a master sheet. Mean and standard deviation was assessed. Frequency and percentage distribution of sample characteristic. Chi- square analysis to association between pre-tests level of knowledge and socio demographic variables.

\section{Results}

The socio demographic variables in frequency and percentage reveals that maximum subjects $71.66 \%$ (43) were male, $58.33 \%$ (35) were in the age group of $21-30$ years, among them $61.66 \%$ (37) were graduated, 51\% (85) hailing from urban background. Regarding using computer $63.33 \%$ (38) were using computer $>4$ hours in a day, majority of subjects $63.33 \%$ (38) having vision problem after using computer, maximum subjects $60 \%$ (36) were doing other occupation, likewise majority of subjects $45 \%$ (27) were having above 4 years` experience in computer field.

\subsection{Comparison of knowledge scores between pre-test} and post-test by frequency, percentage and total score.

Table 1: $n=60$

\begin{tabular}{|c|c|c|c|c|}
\hline Score & \multicolumn{2}{|c|}{ Pre-test } & \multicolumn{2}{c|}{ Post test } \\
\hline & Frequency & $\%$ & Frequency & $\%$ \\
\hline Good & 3 & 5 & 58 & 96.66 \\
\hline Average & 23 & 38.33 & 2 & 3.33 \\
\hline Poor & 34 & 56.66 & - & - \\
\hline
\end{tabular}

In the pre-test 5\% (3) have good knowledge regarding computer vision syndrome and its prevention. In the post test knowledge level, majority of computer professional $96.66 \%$ (58) has good knowledge regarding computer vision syndrome and its prevention.

5.2 Analysis of pre-test and post-test knowledge score using frequency, percentage and total score.

Table 2: $\mathrm{n}=60$

\begin{tabular}{|c|c|c|c|}
\hline Knowledge & Mean & Mean percentage & Standard deviation \\
\hline Pretest & 15.9 & $49.68 \%$ & 5.023 \\
\hline Post test & 29.75 & $92.96 \%$ & 2.19 \\
\hline
\end{tabular}

Distribution of aspect wise pre-test mean knowledge score was $15.9 \%$, standard deviation of pre-test knowledge score was $5.023 \%$, and mean percentage of pre-test knowledge score was $49.68 \%$. And post-test mean knowledge score was $29.75 \%$, standard deviation of post-test knowledge score was $2.19 \%$, and mean percentage of post-test knowledge score was $92.96 \%$.

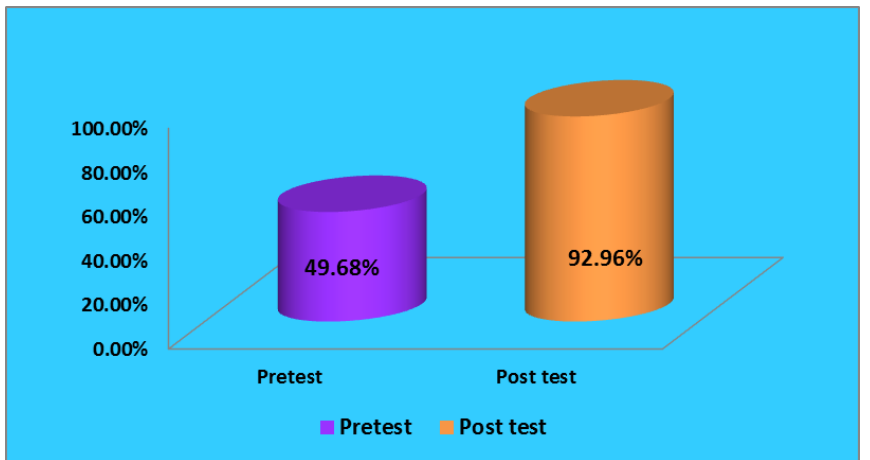

Figure 1: Cylindrical chart showing pre-test and post-test knowledge score mean percentage

Figure 1 reveals that mean percentage of posttest knowledge score was $92.96 \%$.

5.3 Evaluation of data related to effectiveness of selfinstructional module regarding knowledge regarding computer vision syndrome and its prevention using $\mathrm{Z}$ test

Table 3: $\mathrm{n}=60$

\begin{tabular}{|c|c|c|c|c|c|}
\hline Criteria & Mean & $\begin{array}{c}\text { Mean } \\
\text { difference }\end{array}$ & $\begin{array}{c}\text { SD } \\
\text { deviation }\end{array}$ & $\begin{array}{c}\text { SD } \\
\text { error }\end{array}$ & Z-value \\
\cline { 1 - 1 } Pre-test & 15.9 & & 5.02 & & Highly significant \\
\cline { 1 - 1 } Post-test & 29.75 & 13.85 & 2.19 & 0.70 & 19.58 \\
\hline
\end{tabular}

The mean knowledge score of pre-test 15.9 with standard deviation 5.02, mean knowledge score of post-test 29.75 with standard deviation 2.19 , the mean difference is 13.85 .

The statistical paired z- test implies that the difference in the pre-test and post-test knowledge score found highly statistically significant $>0.05$, which proves the effectiveness of self-instructional module. Hence $\mathrm{H} 1$ is accepted and $\mathrm{H} 0$ is rejected.

5.4 Chi square analysis for association between the selected socio demographic variables with pre-test knowledge score of computer professional

Table 4: $\mathrm{n}=60$

\begin{tabular}{|c|c|c|c|c|}
\hline $\begin{array}{c}\text { Socio } \\
\text { demographic } \\
\text { data }\end{array}$ & $\begin{array}{c}\text { Chi-square } \\
\text { value }\end{array}$ & $\begin{array}{c}\text { Degree of } \\
\text { freedom }\end{array}$ & $\begin{array}{c}\text { Critical } \\
\text { value } \\
>0.05\end{array}$ & Inferences \\
\hline Gender & 6.23 & 2 & 5.99 & Significant \\
\hline Occupation & 11.2 & 6 & 12.53 & $\begin{array}{c}\text { Moderately } \\
\text { Significant }\end{array}$ \\
\hline
\end{tabular}

There is significant association between the knowledge scores with selected demographic variables. Hence $\mathbf{H}_{2}$ is accepted. There was significant association between gender and knowledge scores. There was moderately significant association between occupation and knowledge scores. 


\section{International Journal of Science and Research (IJSR) \\ ISSN (Online): 2319-7064}

Index Copernicus Value (2013): 6.14 | Impact Factor (2014): 5.611

\section{Discussion}

In this study the comparison of knowledge scores between pre-test and post-test in which 5\% (3) have good knowledge regarding computer vision syndrome and its prevention in the pre-test. In the post test knowledge level, majority of computer professional $96.66 \%$ (58) has good knowledge regarding computer vision syndrome and its prevention.

Analysis of pre-test and post-test knowledge score using frequency, percentage and total score. The distribution of aspect wise pre-test mean knowledge score was $15.9 \%$, standard deviation of pre-test knowledge score was $5.023 \%$, and mean percentage of pre-test knowledge score was $49.68 \%$. And post-test mean knowledge score was $29.75 \%$, standard deviation of post-test knowledge score was $2.19 \%$, and mean percentage of post-test knowledge score was $92.96 \%$.

The effectiveness of self-instructional module regarding knowledge regarding computer vision syndrome and its prevention using Z- test. The mean knowledge score of pretest 15.9 with standard deviation 5.02, mean knowledge score of post-test 29.75 with standard deviation 2.19 , the mean difference is 13.85 .

The statistical paired z- test implies that the difference in the pre-test and post-test knowledge score found highly statistically significant $>0.05$, which proves the effectiveness of self-instructional module. Hence $\mathbf{H 1}$ is accepted and $\mathbf{H O}$ is rejected. Association between the selected socio demographic variables with pre-test knowledge score of computer professional. There is significant association between the knowledge scores with selected demographic variables. Hence $\mathbf{H}_{2}$ is accepted.

There is association between the pretest knowledge score and gender as the calculated value is 6.23 is greater than the table value of chi-square (5.99) at level of $5 \%$ level of significance.

This finding is also supported by study to evaluate the role of Akshitarpana, Shirodhara and an ayurvedic compound in childhood computer vision syndrome (June-2011). The highesr incidence of computer vision syndrome was seen in the male group because girls usually obey more to parents and hesitate to avoid the instructions, boys becoming more stubborn to watch TV and computer [13].

There is association between the pretest knowledge score and occupation as the calculated value is 11.2 is near to the table value of chi-square (12.5) at level of $5 \%$ level of significance.

This finding is also supported by study Zairina A. Rahman, September 2011. Computer User: Demographic and Computer Related Factors that Predispose User to Get Computer Vision Syndrome. In this study the maximum samples were Administrative 330 (75.7\%) [14]

\section{References}

[1] Pooja Bagdi, Swati Rathore, Kamal Singh Rathore, Para 1,Mar04,2010,http:/www.articlesbase.com/newslettersarticles/computer-vision-syndrome-an-update1938126.html

[2] Anshel Jeffrey, - Visual Ergonomics In The Work Place," First Edition, London, Taylor and Francis LTD, Pg. 37, 1998

[3] Anshel Jeffrey, - Visual Ergonomics In The Work Place," First Edition, London, Taylor and Francis LTD, Pg. 37, 1998

[4] Mbaye I, Fall M .C, Segnon A., Survey Of Pathology Associates Use Of VDT," Dakar medicine, 43(1), Pg. 37 - 40, January 1998.

[5] Grant A .H, Factors Influencing Hand / Eye Synchronicity In Computer Age," Optometry and Vision Syndrome, 69(9), Pg. 939 - 44, September, 1992.

[6] Sheedy J .E., Reading Performance And Visual Comfort On A High Resolution Monitor Compared To A VGA Monitor," Journal Of Electronic Imaging, 1(4), Pg. 405 - 410, April, 1992

[7] Punnett Laura And Robin Herbert, Work Related Musculoskeletal Disorders: Is There A Gender Difference And If So, What Does It Mean?," Department Of Work Environment, University Of Massachusetts, Mount Minai School Of Medicine, 2002.

[8] Gary Heiting ,and Larry K.Wan,Children and Computer Vision Syndrome [citedoninternetApril2014], availableathttp://www.allabo utvision.com/cvs/children-computer-visionsyndrome.htm

[9] Garry Jacobs, Employment Potential in the IT Industry February 2001, avalible at http://www.motherservice.org/content/employmentpotential-it-industry

[10]Tornq Vist Wigaeus, Hagman Maud And Others, Gender Aspects Of Working Conditions And Musculo Skeletal Health Among Professional Computer User,' Programme For Ergonomics, National Institute For Working Life, Stockholm, Sweden 2002.

[11] Abida Ellahia, M. Shahid Khalilb, Fouzia Akrama, Computer Users At Risk: Health Disorders Associated With Prolonged Computer Use," Vol.2(4), Pg. 171-182, October, 2011.

[12] Jatinder Bali, Neeraj Navin, Bali Renu Thakur, Computer Vision Syndrome : A Study Of The Knowledge, Attitudes And Practices In Indian Ophthalmologists," Delhi., India, Nov 8, 2011.

[13] Singh Omendra Pal, Singh Laxmi, Kumar Abhimanyu, - AClinical Study To Evaluate The Role Of Akshit Arpana, Shirodhara And An Ayurvedic Compound In Childhood Computer Vision Syndrome," India, 2 (3), Pg. 708 - 714, June, 2011.

[14]Zairina A. Rahman, Computer User: Demographic And Computer Related Factors that Predispose User To Get Computer Vision Syndrome," Vol. 1, No. 2; September, 2011. 


\section{Author Profile}

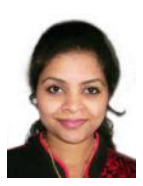

Mrs. Shiny .T. Sam, MSc (N). completed Master of Science in Nursing (Medical Surgical Nursing) from Shri Shankaracharya College of Nursing, Bhilai, under AYUSH And Healh Science University of Chhattisgarh in 2012 and BSc (N) from the same institute Shri Shankaracharya College of Nursing, Bhilai, Chhattisgarh in 2009.worked as staff nurse NICU at JLN Hospital Bilai. Working as Lecturer in Medical Surgical Nursing Department, MGM Muthoot College of Nursing, Pathanamthitta, Kerala .

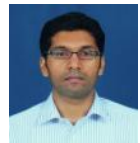

Mr. Rinu J George MSc (N) completed his Bachelor of Science in Chemistry from Mahatma Gandhi University. He received his Bachelor Science in Nursing from Bapuji College of Nursing attached to JJ Medical College under Rajiv Gandhi University Of Health Sciences and completed his Master of Science in Nursing (Child Health Nursing) from Sri Siddartha College Of Nursing under RGUHS. He has published articles and research papers amenable to nursing in various national and international journals. He formerly worked as Assistant professor, Pediatric Nursing department, Sree Gokulam Nursing College, Trivandrum, Kerala [India]. Currently he is working as Senior Lecturer, JIMMA University, Ethiopia. 